\title{
New Rhenium Octahedral Cluster Sulfido-cyanide Chain Polymer: The Synthesis and Crystal Structure of $\mathrm{Cs}_{4}\left[\left\{\operatorname{Re}_{6} \mathrm{~S}_{8}\right\}(\mathrm{CN})_{4} \mathrm{~S}_{2 / 2}\right]$
}

\author{
N. G. Naumov, ${ }^{*}$ S.-J. Kim, ${ }^{\dagger, *}$ A. V. Virovets, Y. V. Mironov, and V. E. Fedorov \\ Nikolaev Institute of Inorganic Chemistry, Siberian Branch of the Russian Academy of Sciences, 3, Acad. \\ Lavrentievpr.,Novosibirsk,630090,Russia."E-mail:naumov@che.nsk.su \\ ${ }^{\dagger}$ Department of Chemistry, Ewha Womans University, Seoul 120-750, Korea. *E-mail: sjkim@ewha.ac.kr \\ Received December 27, 2005
}

Key Words : Rhenium, Cluster, Cyanide, Polymer, Crystal structure

The chemistry of rhenium octahedral cluster chalcogenides demonstrates a rich diversity of types of chain-like, layered and framework structures as well as bridging ligands between clusters. The clusters can be connected via $\mu_{3}$ inner ligands of cluster units, ${ }^{1}$ apical halogenide ligands, ${ }^{2}$ complex telluride $\mathrm{Te}_{6}$ or $\mathrm{Te}_{7}{ }^{3,4}$ and halogen-telluride $\mathrm{Te}_{8} \mathrm{Q}_{18}{ }^{2-}$ groups, $\mathrm{Q}=\mathrm{Cl}, \mathrm{Br}^{3}$, chalcogenides, dichalcogenide and trichalcogenide ligands. ${ }^{5-7}$ The latter family described by Prof. W. Bronger (so called "Bronger phases") seems to be most numerous and complete family of polymeric rhenium octahedral cluster chalcogenides with various bridges and connectivity between clusters. For example, $\operatorname{Li}_{4} \operatorname{Re}_{6} \mathrm{~S}_{11}{ }^{7}$ contains $\mathrm{Re}_{6} \mathrm{~S}_{8}$ cluster units connected by six bridging $m_{2}$ sulfido ligands that gave $\mathrm{Li}_{4}\left[\left\{\operatorname{Re}_{6} \mathrm{~S}_{8}^{\mathrm{i}}\right\}(\mathrm{S})^{\mathrm{a}-\mathrm{a}}{ }_{6 / 2}\right]_{\infty 0_{\infty} \infty \infty}$ framework according to Schafer notation. ${ }^{8}$

Recently it was shown that reaction of $\mathrm{ReS}_{2}$ with $\mathrm{KCN}$ at elevated temperature leads to formation an unique layered compound $\mathrm{K}_{4} \operatorname{Re}_{6} \mathrm{~S}_{10}(\mathrm{CN})_{2}{ }^{9}$ In this polymer the $\mathrm{Re}_{6} \mathrm{~S}_{8}$ units are linked into two-dimensional grids by sharing four apical sulphide ligands. Additionally two "trans" rhenium atoms in cluster core are coordinated by terminal cyano-groups. Thus, crystallographic formula of this compound may be written according to Schafer notation as $\mathrm{K}_{4}\left[\left\{\operatorname{Re}_{6} \mathrm{~S}_{8}^{\mathrm{i}}\right\}(\mathrm{CN})_{2}^{\mathrm{a}}{ }_{2}(\mathrm{~S})^{\mathrm{a}-\mathrm{a}}{ }_{4 / 2}\right]_{\infty \infty \infty}$. From formal point of view this compound could be presented as cleavage of two Re- $\mu_{2} \mathrm{~S}-\mathrm{Re}$ bridges in $\left[\left\{\operatorname{Re}_{6} \mathrm{~S}_{8}^{\mathrm{i}}\right\}(\mathrm{S})^{\mathrm{a}-\mathrm{a}}{ }_{6 / 2}\right]$ and substitution of them by terminal cyano-ligands. In present work we report the synthesis and crystal structure of new chain polymer $\mathrm{Cs}_{4}\left[\left\{\operatorname{Re}_{6} \mathrm{~S}_{8}^{\mathrm{i}}\right\}(\mathrm{CN})^{\mathrm{a}}{ }_{4}(\mathrm{~S})^{\mathrm{a}-\mathrm{a}}{ }_{2 / 2}\right]_{\infty}$ which is the next member of a series $\mathrm{M}_{4}\left[\left\{\operatorname{Re}_{6} \mathrm{~S}_{8}^{\mathrm{i}}\right\}(\mathrm{CN})^{\mathrm{a}}{ }_{2 \mathrm{x}}(\mathrm{S})^{\mathrm{a}-\mathrm{a}}\left({ }_{(6-2 \mathrm{x}) / 2}\right]\right.$, where $\mathrm{M}$ is alkali metal. This compound was obtained with high yield by high temperature reaction of $\mathrm{ReS}_{2}$ with $\mathrm{KCN}$ in presence of $\mathrm{CsCl}$ excess. $^{10}$

$\mathrm{X}$-ray structural analysis ${ }^{11,12}$ revealed that compound $\mathrm{Cs}_{4}\left[\operatorname{Re}_{6} \mathrm{~S}_{8}(\mathrm{CN})_{4} \mathrm{~S}_{2 / 2}\right]$ is built from octahedral rhenium cluster units $\left\{\operatorname{Re}_{6} \mathrm{~S}_{8}\right\}$. All atoms in the unit cell are lying in general Wyckoff $2 i$ positions. Six crystallographically independent rhenium atoms and eight sulfur atoms form two centrosymmetric cluster units $\operatorname{Re}_{6}\left(\mu_{3}-\mathrm{S}\right)_{8}$ (Figure 1). Interatomic distances Re-Re are: mean: 2.606[9] $\AA$, min-max: 2.5924(11) $\div 2.6201(11) \AA$ that are comparable within the Re-Re single bonds usually observed in octahedral rhenium clusters with $\operatorname{Re}_{6}\left(\mu_{3}-\mathrm{S}\right)_{8}$ cluster cores, e.g. in $\mathrm{Li}_{4} \operatorname{Re}_{6} \mathrm{~S}_{11}{ }^{7}$ in $\mathrm{K}_{4}\left[\operatorname{Re}_{6} \mathrm{~S}_{10}(\mathrm{CN})_{2}\right]^{9}$

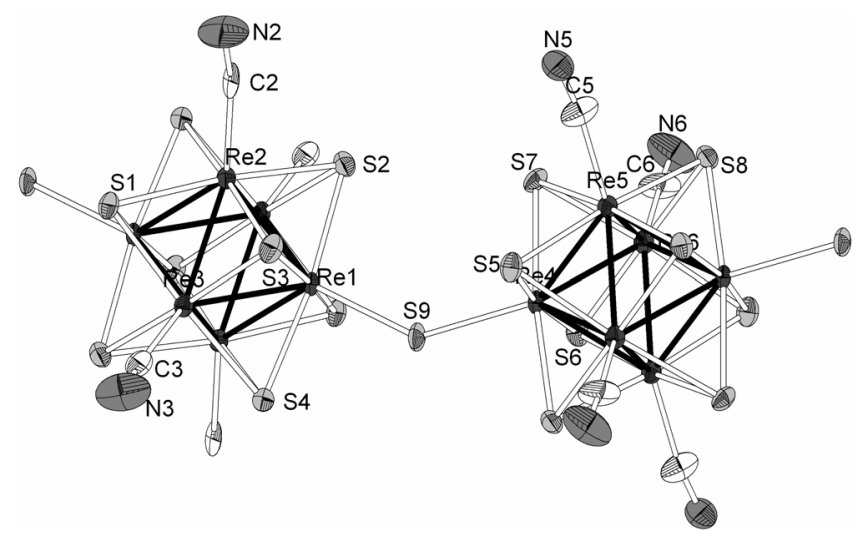

Figure 1. Two independent $\operatorname{Re}_{6} \mathrm{~S}_{8}$ cluster units bridged by $\mu_{2}-\mathrm{S}$ ligand in the structure of $\mathrm{Cs}_{4}\left[\operatorname{Re}_{6} \mathrm{~S}_{8}(\mathrm{CN})_{4} \mathrm{~S}_{2 / 2}\right]$.

and in $\mathrm{Cs}_{3} \mathrm{~K}\left[\operatorname{Re}_{6} \mathrm{~S}_{8}(\mathrm{CN})_{6}\right] \cdot{ }^{13} \mathrm{Re}-\mu_{3}-\mathrm{S}$ vary from $2.384(6)$ to $2.422(6)$, mean $2.406(10) \AA$. These values are also typical for $\operatorname{Re}_{6}\left(\mu_{3}-\mathrm{S}\right)_{8}$ cluster unit.

These cluster units are linked via two trans- $\mu_{2}-\mathrm{S}$ ligands to form the infinite chains running along $a$ axis (Figure 2). The

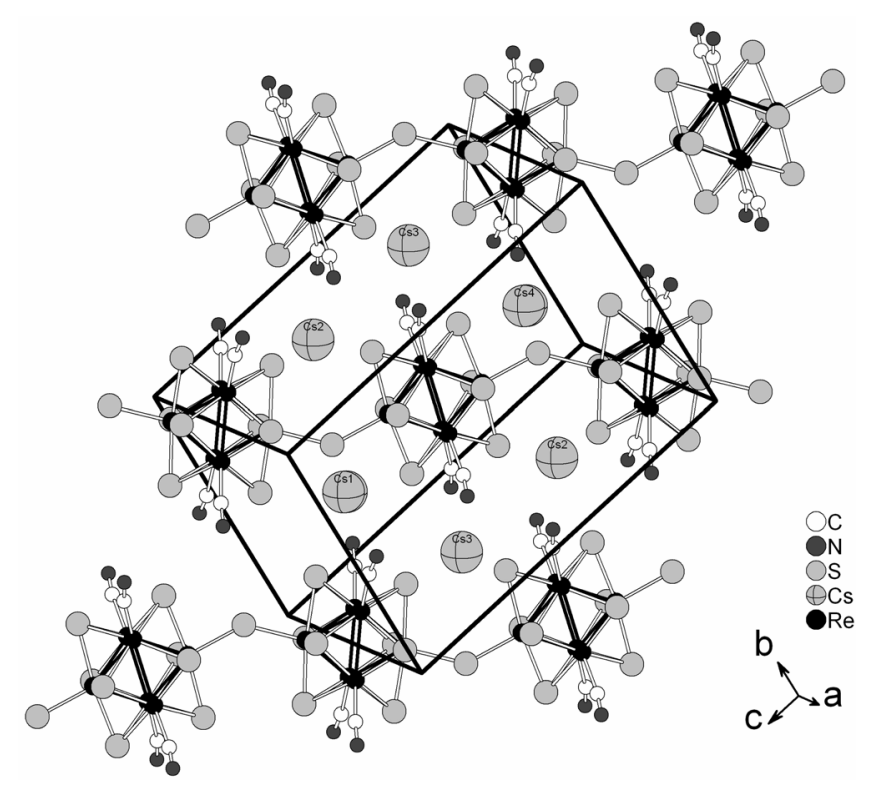

Figure 2. Crystal packing in the structure of $\mathrm{Cs}_{4}\left[\operatorname{Re}_{6} \mathrm{~S}_{8}(\mathrm{CN})_{4} \mathrm{~S}_{2 / 2}\right]$. 
bridge is bent with $\operatorname{Re}-\left(\mu_{2}-\mathrm{S}\right)$-Re angle $137.6(3)^{\circ}$ and $\operatorname{Re}-\mu_{2}-$ $\mathrm{S}$ distances are equal to $2.400(5)$ and 2.402(5) $\AA$. The mean $\mathrm{Re}-\mathrm{C}(2.16 \AA)$ and $\mathrm{C}-\mathrm{N}(1.08 \AA)$ bond distances have their typical values. These chains are packed in $b c$ plane in pseudohexagonal manner with $\mathrm{Cs}^{+}$cations allocated between them. Cesium atoms are located in general positions which are fully occupied. Each cluster unit is surrounded by 12 Cs atoms forming slightly distorted cubooctahedron. The cesium cations make contacts with both $\mu_{3}$ - and $\mu_{2}$-S ligands and with $\mathrm{C}$ and $\mathrm{N}$ atoms of $\mathrm{CN}$ ligands with distances Cs-S of

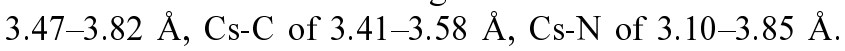
No $\mathrm{Cs} / \mathrm{K}$ mixing was found according to structural analysis and EDAX.

Comparison of 1D structure in the title compound with 2D in $\mathrm{K}_{4}\left[\operatorname{Re}_{6} \mathrm{~S}_{10}(\mathrm{CN})_{2}\right]$ and $3 \mathrm{D}$ in $\mathrm{Li}_{4}\left[\operatorname{Re}_{6} \mathrm{~S}_{11}\right]$ demonstrated notable elongation of Re- $\mu_{2}$-S bonds from $\sim 2.40$ to $\sim 2.49 \AA$ with increase of number Re- $\mu_{2}-\mathrm{S}$ bridges. In the same time the Re- $\mu_{2}$-S-Re fragment seems to be flexible, angle on $\mathrm{S}$ varying from 118.8(2) in $\mathrm{Cs}_{4}\left[\mathrm{Re}_{6} \mathrm{~S}_{9}(\mathrm{CN})_{4}\right]$ to $152.8(5)$ in $\mathrm{Li}_{4}\left[\operatorname{Re}_{6} \mathrm{~S}_{11}\right]$.

We have found that in the reaction of $\mathrm{ReS}_{2}$ with molten $\mathrm{KCN} / \mathrm{CsCl}$ mixture an increase in temperature up to 750 $800{ }^{\circ} \mathrm{C}$ suppresses a formation of the title compound and favors formation of a compound with composition $\mathrm{Cs}_{8}\left[\operatorname{Re}_{12} \mathrm{CS}_{17}(\mathrm{CN})_{6}\right]$. The last compound is the cesium analog of $\mathrm{K}_{8}\left[\mathrm{Re}_{12} \mathrm{CS}_{17}(\mathrm{CN})_{6}\right]$ salt having twelve nuclear rhenium cluster with interstitial $\mu_{6}$ carbon atom. The dissolution of this compound in hot water followed partial oxidation of cluster anion resulted in formation of $\mathrm{Cs}_{6}\left[\operatorname{Re}_{12} \mathrm{CS}_{17}(\mathrm{CN})_{6}\right]$ reported very recently. ${ }^{14}$ The identity was confirmed by comparison of UV-Vis spectra and X-ray powder diffraction patterns. ${ }^{15}$

It is interesting to note that chain-like compound $\mathrm{Cs}_{4}\left[\mathrm{Re}_{6} \mathrm{~S}_{8}(\mathrm{CN})_{4} \mathrm{~S}_{2 / 2}\right]$ obtained can be dissolved by heating in aqueous solution of $\mathrm{KCN}$, and at the same time monomeric $\left[\operatorname{Re}_{6} \mathrm{~S}_{8}(\mathrm{CN})_{6}\right]^{4-}$ anion is formed.

Thus, high temperature chemistry of rhenium chalcogenides still demonstrates fascinating variety of new thermodynamically stable compounds at variation of reaction conditions (temperature, stoichiometry, presence of additional cations, etc. . ${ }^{6,16}$ The title compound completes a homologous series of octahedral cluster anions $\left[\operatorname{Re}_{6} \mathrm{~S}_{8} \mathrm{~S}_{6 / 2}\right]^{4-},\left[\operatorname{Re}_{6} \mathrm{~S}_{8}(\mathrm{CN})_{2} \mathrm{~S}_{4 / 2}\right]^{4-}$, $\left[\operatorname{Re}_{6} \mathrm{~S}_{8}(\mathrm{CN})_{4} \mathrm{~S}_{2 / 2}\right]^{4-}$ and $\left[\operatorname{Re}_{6} \mathrm{~S}_{8}(\mathrm{CN})_{6}\right]^{4-}$ which could be described as consequent cleavage of $\mathrm{Re}-\mu_{2} \mathrm{~S}-\mathrm{Re}$ bridges and substitution of bridged sulphur atoms by terminal cyanoligands.

Acknowledgements. This work was supported by the SRC program of the Korea Science and Engineering Foundation (KOSEF) through the Center for Intelligent Nano-Bio Materials at Ewha Womans University (grant R11-2005008-00000-0) and Russian Foundation for Basic research (grant 05-03-08090).

\section{References}

1. (a) Leduc, L.; Perrin, A.; Sergent, M. Acta Crystallogr. C Cryst. Str. 1983, C39, 1503. (b) Long, J. R.; Williamson, A. S.; Holm, R. H. Angew. Chem. Int. Ed. 1995, 34, 226. (c) Pilet, G.; Hernandez, O.; Perrin, A. Z. Krist. New Cryst. Struct. 2002, 217, 11.

2. Perrin, A.; Leduc, L.; Sergent, M. Eur. J. Solid State Inorg. Chem. 1991, 28, 919

3. Mironov, Y. V.; Pell, M. A.; Ibers, J. A. Angew. Chem. Int. Ed. 1996, 35, 2854.

4. Fedorov, V. E.; Podberezskaya, N. V.; Mishchenko, A. V.; Khudorozhko, G. F.; Asanov, I. P. Mater. Res. Bull. 1986, 21, 1335.

5. (a) Spangenberg, M.; Bronger, W. Angew. Chem. 1978, 90, 382. (b) Bronger, W.; Miessen, H. J.; Neugroeschel, R.; Schmitz, D.; Spangenberg, M. Z. Anorg. Allg. Chem. 1985, 525, 41. (c) Bronger, W.; Loevenich, M.; Schmitz, D.; Schuster, T. Z. Anorg. Allg. Chem. 1990, 587, 91. (d) Bronger, W.; Loevenich, M.; Schmitz, D. J. Alloys Compounds 1994, 216, 25.

6. Bronger, W. Ternary Rhenium and Technetium Chalcogenides Containing $\operatorname{Re}_{6}$ and Tc $\mathrm{c}_{6}$ Clusters in Metal Clusters in Chemistry; Wiley-VCH: Weinheim; New York; Chichester; Brisbane; Singapore; Toronto, 1999; Vol. 3.

7. Bronger, W.; Miessen, H. J.; Mueller, P.; Neugroeschel, R. J. LessCommon Met. 1985, 105, 303.

8. Schafer, H.; von Schnering, H. G. Angew. Chem. 1964, 76, 833.

9. Mironov, Y. V.; Fedorov, V. E.; McLauchlan, C. C.; Ibers, J. A. Inorg. Chem. 2000, 39, 1809.

10. The mixture of $\operatorname{ReS}_{2}(0.200 \mathrm{~g}, 0.799 \mathrm{mmol}), \mathrm{KCN}(0.200 \mathrm{~g}, 3.07$ $\mathrm{mmol})$ and $\mathrm{CsCl}(0.300 \mathrm{~g}, 1.78 \mathrm{mmol})$ were heated in evacuated quartz tube at $650{ }^{\circ} \mathrm{C}$ for $48 \mathrm{hrs}$. After cooling down the dark red single crystals for $\mathrm{X}$-ray analysis were selected from reaction mixture. The reaction product was washed with water and dried on air. Yield: $0.255 \mathrm{~g}(93.8 \%)$. According to XRD pattern, polycrystalline sample did not contain any additional peaks. IR $(\mathrm{KBr}), \mathrm{cm}^{-1}: 399,406,414,2117$. Energy dispersive analysis showed absence of noticeable amounts of $\mathrm{K}$ and $\mathrm{Cl}$ in crystals and adequate agreement of $\mathrm{Cs}: \mathrm{Re}: \mathrm{S}$ ratio to structural data.

11. Crystal data for $\mathrm{Cs}_{4}\left[\operatorname{Re}_{6} \mathrm{~S}_{8}(\mathrm{CN})_{4} \mathrm{~S}_{2 / 2}\right]: \mathrm{C}_{4} \mathrm{Cs}_{4} \mathrm{~N}_{4} \mathrm{Re}_{6} \mathrm{~S}_{9}, \mathrm{M}=2041.46$, red plate, $0.064 \times 0.047 \times 0.022 \mathrm{~mm}^{3}$, triclinic, space group P-1 (No. 2), $\mathrm{a}=9.9153(6), \mathrm{b}=10.0002(5), \mathrm{c}=15.1053(10) \mathrm{A}, \alpha=$ 102.347(3), $\beta=107.685(3), \gamma=101.744(2)^{\circ}, \mathrm{V}=1334.71(14) \mathrm{A}^{3}$, $\mathrm{Z}=2, \mathrm{D}_{\text {calc }}=5.080 \mathrm{~g} / \mathrm{cm}^{3}$, Bruker X8Apex CCD detector, MoK $\alpha$ radiation, $1=0.71073 \mathrm{~A}, \mathrm{~T}=293(2) \mathrm{K}, 2 \theta_{\max }=55.0^{\circ}, 13209$ reflections collected, 5953 unique (Rint $=0.0420$ ). The structure was solved and refined using the programs SHELXS-97 and SHELXL $-97^{12}$ respectively. Final GooF $=1.164, \mathrm{R} 1=0.0544$, $\mathrm{wR} 2=0.1581, \mathrm{R}$ indices based on 4766 reflections with $\mathrm{I}>$ 2sigma(I) (refinement on $\mathrm{F}^{2}$ ), 244 parameters, 0 restraints. Lp and absorption corrections applied, $\mu=33.181 \mathrm{~mm}^{-1}$.

12. Sheldrick, G. M. SHELXL-97, Program for Crystal Structure Refinement, Gottingen; Sheldrick, G. M. SHELXS-97, Program for Crystal Structure Solution, Gottingen.

13. Slougui, A.; Mironov, Y. V.; Perrin, A.; Fedorov, V. E. Croat. Chem. Acta 1995, 68, 885.

14. Mironov, Y. V.; Naumov, N. G.; Kozlova, S. G.; Kim, S.-J.; Fedorov, V. E. Angew. Chem. Int. Ed. 2005, 44, 6867.

15. Experimental data for $\mathrm{Cs}_{6}\left[\operatorname{Re}_{12} \mathrm{CS}_{17}(\mathrm{CN})_{6}\right]$ : EDAX: Cs:Re:S $=5.9$ : $12: 16.2$; XRD: hexagonal, $a=9.73(1), c=14.63(5) \AA$, UV-Vis (aqueous solution), mn: 330 (s), 360 (s), 445 (sh), 505 (m), 605 (sh), $735(\mathrm{w})$.

16. (a) Saito, T. J. Chem. Soc., Dalton Trans. 1999, 97. (b) Gabriel, J. C. P.; Boubekeur, K.; Uriel, S.; Batail, P. Chem. Rev. 2001, 101, 2037. (c) Gray, T. G. Coord. Chem. Rev. 2003, 243, 213. (d) Pilet, G.; Perrin, A. C. R. Chimie 2005, 8, 1728. 